\title{
Obstrüktif Uyku Apne Sendromu ve Narkolepsi Birlikteliği: Dört Olgu
}

\section{Coexistence of Obstructive Sleep Apnea Syndrome and Narcolepsy: Four Cases}

\author{
(1) Dilara Mermi Dibek, (1) Onur Bulut, (1) Sevgi Ferik, (1) Ayşegül Özer Çelik, (D) İbrahim Öztura, (1) Barış Baklan
}

Dokuz Eylül Üniversitesi Tıp Fakültesi, Nöroloji Anabilim Dalı, Izmir, Türkiye

\section{Öz}

Obstrüktif Uyku Apne sendromu ve narkolepsi hastalarının klinik başvurusu ortak olarak gündüz aşırı uykululuğudur. Her ne kadar her iki medikal durumun gündüz aşırı uykululuk özellikleri ve eşlik eden semptomatolojisi birbirinden farklı olabilse de bazı olgularda ayırt edici özellikler maskelenebilmektedir. Bildirilen dört olgumuzda Obstrüktif Uyku Apne sendromu ve narkolepsi tip 1 birlikteliği mevcuttur. Bu durumun komorbidite olabilmesi, birlikteliklerinde tipik kliniklerini maskeleyebilmeleri veya birbirlerinin risk faktörlerini doğurma olasılığını tartışmayı hedefledik.

Bildirilerilen olguların ikisinde gündüz aşırı uykululuğu ile başvurusunda, uyku ataklarının dinlendirici olmaması ve tipik katapleksi atakları tanımlanmamasına rağmen tespit edilen Uyku Apne sendromu tedavisini aldıklarında gündüz aşırı uykululukları devam etse de katapleksi atakları tanımlanmaya başlanmıştır. Tekrarlanan tanı testleri sonucunda, uyku apne sendromuna ek olarak narkolepsi tanısı almışlardır. Diğer iki olgumuzda ise gündüz aşırı uykululuğu ve katapleksi atakları ile tanı testleri tip 1 narkolepsiye işaret etse de klinik izlemde Vücut Kitle indekslerinin artışı ile de tekrarlanan tanı testinde Uyku Apne sendromu eşlik ettiği görülmüştür. Bu dört olguya yaklaşımı bildirerek nedenlerini ve olası mekanizmalarını belirtmeyi hedefledik.

Anahtar Kelimeler: Narkolepsi, Uyku Apne sendromu, gündüz aşırı uykululuğu, birliktelik

\begin{abstract}
Excessive daytime sleepiness is a common clinical application of Obstructive Sleep Apnea syndrome and narcolepsy patients. Although both medical conditions can be different in extensive daytime sleepiness features and accompanying symptomatology, distinctive features may be masked in some cases. In our four reported cases, there were obstructive sleep apnea syndrome and narcolepsy type 1 coexistence. We aimed to discuss the possibility of this condition being comorbidity, the possibility of masking the type clinics in their association or the possibility of causing each other's risk factors.

In two of the reported cases, although excessive daytime sleepiness was not restful and typical cataplexy attacks were not described in the beginning, cataplexy attacks started to be defined even when excessive daytime sleepiness persisted when they were treated with Sleep Apnea syndrome. As a result of repeated diagnostic tests, they were diagnosed with narcolepsy in addition to Sleep Apnea syndrome. In the other two cases, excessive daytime sleepiness and cataplexy attacks, and diagnostic tests indicated type 1 narcolepsy, but it was observed that the Body Mass indexes were increased in the clinical follow-up and sleep apnea syndrome was diagnosed with repeated test. By presenting the approach to these four cases, we aimed to identify the causes and possible mechanisms about coexistence between narcolepsy and sleep apnea syndrome.
\end{abstract}

Keywords: Narcolepsy, Sleep Apnea syndrome, daytime sleepiness, coexistence

\section{Giriş}

Gündüz aşırı uykululuğu, uzun uyanıklık periyodunda uykuya meyil veya uyku ihtiyacının varlığı olarak tanımlanmakta; genel popülasyonda hekime başvurmada günlük yaşam kalitesini belirli ölçüde etkileyen bir semptomdur $(1,2)$. Bu semptomla gelen hastalarda; semptomun ne zamandan itibaren olduğu, gece uyku periyodu ve uyku hijyen uyumu, kullanılan medikasyon varlığı, uzun uyku periyodlarının süresi ve kalitesi,

kadın cinsiyette menstruel periyotla ilişkisi, eşlik eden katapleksi atakları, uykuda bacak hareketleri veya parasomni varlığı, uyku paralizileri, hipnogojik veya hipnopompik halüsinasyonları, gece uyku bölünmeleri, uykuda nefes tıkanmaları, horlamaları, uykudan tıkanarak uyanmaları, geceleri göğüs üstü-boyun kısmında terleme varlığı özellikle ayrıntılandırılarak öykü alınır (3). Sistemik ve nörolojik muayene ardından, gündüz aşırı uykululuğunun derecelendirildiği, subjektif bir test olan Epwoth Uyku skalasını uygulayarak şiddeti belirlenir; bir ön tanı

Yazışma Adresi/Address for Correspondence: Dr. Dilara Mermi Dibek, Dokuz Eylül Üniversitesi Tıp Fakültesi, Nöroloji Anabilim Dalı, İzmir, Türkiye

Tel.: +90 2324125059 E-posta: dilara_mermi@hotmail.com ORCID-ID: orcid.org/0000-0001-9963-9450

Geliş Tarihi/Received: 26.10.2019 Kabul Tarihi/Accepted: 02.01.2020

๑Telif Hakkı 2020 Türk Uyku Tıbbı Derneği / Türk Uyku Tıbbı Dergisi, Galenos Yayınevi tarafından basılmıştır. 
oluştuktan sonra tiroit fonksiyon testleri veya kranial manyetik rezonans görüntüleme (MRG) gibi ek tetkiklerle birlikte gece uyku süreleri ve uyku periyotlarını görüntülemek, eşlik eden uykuda anormal solunum olayı olup olmadığını görmek amacı ile polisomnografi (PSG) tetkiki yapılır. Ardından test uygulama kuralları çerçevesinde Objektif Gündüz Aşırı Uykululuk ölçeği olarak çoklu uyku latans testi (ÇULT) uygulanır. Hastalarda bir tanı kararı ardından uygun tedavi seçeneğine yönlenilir; ancak bazı hastalarda ise tanı sonrası tedavi izleminde gündüz aşııı uykululukları eder. Bu noktada uygulanan tedavi yeterlilikleri göz önüne alınmakla birlikte eşlik edebilecek komorbid durum varlığı akla gelmelidir.

Kliniğimize gündüz aşırı uykululuğu nedeniyle başvuran, etyolojide narkolepsi ve Obstrüktif Uyku Apne sendromu (OUAS) birlikte yer alan dört olguyu sunarak bu iki medikal durumun komorbidite olarak birliktelik mi hastalıktaki doğal sürecin getirdiği bir komplikasyon mu olduğu yönünden literatür eşliğinde tartışmayı hedefledik.

\section{Olgu Sunumu}

\section{Olgu 1}

Otuz altı yaşında, sağ el dominant, polyester fabrikasında üretim biriminde çalışmakta olan erkek hastaya; yaklaşık on beş yıldır olan horlama, uykuda nefes durmaları ve gündüz aşırı uykululuk şikayetleri ile Şubat 2017 yllında doktor başvurusunda OUAS tanısı ile positive-airway pressure (PAP) tedavisi başlanıyor. Hastanın etkin cihaz kullanımına karşın gündüz uyuklamaları devam etmesi üzerine uyku polikliniğimize başvurusunda öyküsü ayrıntılandırıldığında, son 3-4 yıldır ani kas tonus boşalmaları, boşluğa düşer gibi yığılma atakları olduğu tanımlamaktadır. Özgeçmişinde hipertansiyon nedenli anti-hipertansif kullanımı, nöropatik ağrı nedeniyle pregabalin $75 \mathrm{mg} / g u ̈ n$ ve duloksetin $30 \mathrm{mg} / \mathrm{gün}$ kullanan hastanın soygeçmişinde özellik olmayıp boyu 176 santimetre $(\mathrm{cm})$ vücut ağırlığı 103 kilogram $(\mathrm{kg})$ olup sistemik ve nörolojik muayenesinde patoloji tespit edilmiyor. Laboratuvar tetkiklerinde tiroit fonksiyon testleri ve biyokimyası normal, kranial MRG normal olarak tespit ediliyor. Hastanın gündüz aşıı uykululuğu, katapleksi atakları olması nedeniyle narkolepsi tip 1 ön tanısı ile PAP cihazı ile PSG kaydı alınarak ertesi gün ÇULT planlanıyor. Yapılan cihazı ile PSG incelemesinde (Figür 1) anormal solunum olayı saptanmayıp uykunun 3. dakikasında hızlı göz hareketi (REM) uyku evresi kayıtlanmış ertesi gün yapılan 5 napli çoklu uyku latans testinde ortalama uyku başlangıç latansı 3,4 dakika saptanıp, 5 adet uykuyla başlayan-REM (SO-REM) periyodu kayıtlanarak hasta tip 1 narkolepsi tanısı aldı. Hastanın OUAS nedenli cihaz kullanımı devam etmekte iken narkolepsi hastalığı açısından aşırı uykululuk semptomatik tedavisi için $400 \mathrm{mg} / \mathrm{gün}$ modafinil, $250 \mathrm{mg} /$ gün armodafinil ve metilfenidat tedavisine yanıt alınamaması nedeniyle tedavide 7,5 gr/gün dozuna titre edilen sodyum oksibat kullanılmakta ve nöropatik ağrı nedenli kullandığı pregabalin ve duloksetin tedavisi şikayetlerinin olmaması nedeniyle kesiliyor.

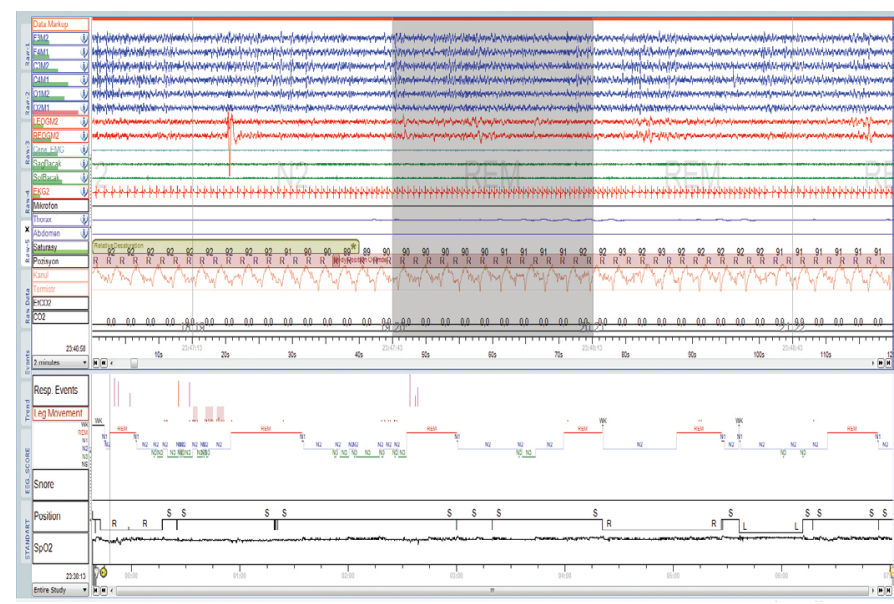

Figür 1. Olgu 1 pozitif havayolu basıncı cihazı ile yapılan polisomnografi incelemesi

Hasta, OUAS için aldığı PAP tedavisi ve narkolepsi nedeni ile verilen sodyum oksibat tedavisi ile yapılan kontrol vizitlerinde katapleksi atakları ve gündüz aşırı uykululuğu olmadan izlenmektedir.

\section{Olgu 2}

Altmış yaşında, sağ el dominant, emekli erkek hastanın; 6-7 yıldır gündüz aşırı uykululuk, horlama, boğularak uyanma, gece uykusu süresince sık uyanma, on bir saat yatakta kalmaya rağmen sabah yorgun uyanma, sık kabus görme, sabah baş ağrısı, gün içinde ani uyku atakları mevcuttur. Özgeçmişinde Koroner Arter hastalığı olan hastanın soygeçmişinde özellik olmayıp, boyu 160 cm, vücut ağırlığı 98 kg, sistemik ve nörolojik muayenesinde patoloji saptanmiyor. Laboratuvar tetkiklerinde tiroit fonksiyon testleri ve biyokimyası normal, kranial MRG normal olarak tespit ediliyor. Hasta uykuda anormal solunum bozukluğu ön tanısı ile yapılan PSG incelemesinde Apne Hipopne indeksi (AHI) 51 saptanarak ağır dereceli Uyku Apne sendromu ile uyumlu değerlendiriliyor ve REM uyku evresinde anormal motor davranışlar kayıtlanıyor. Ağır OUAS tanısı olan ve REM uyku davranış bozukluğu olan hastaya PAP tedavisi veriliyor. PAP titrasyon tedavisi ile davranış bozukluğunda azalma olmasına rağmen gündüz aşıı uykululuğu devam eden hastanın, ek olarak emosyonla tetiklenen ağızda kayma, saniyeler-dakikalar süren ayaklarda güçsüzlük şikayetlerinin de tanımlanması ile hastada narkolepsi birlikteliği ön tanısı ile PAP cihazı ile yapılan PSG incelemesinde anormal solunum olayı olmayıp ertesi gün çoklu uyku latans testinde ortalama uyku başlangıç latansı 3 dakika saptanıp, So-Rem periyodu saptanmıyor. Ancak hastanın takiplerinde cihazı efektif kullanmasına rağmen gündüz uykululuğu ve katapleksi atakları devam etmesi nedeniyle çekimin tekrarlanması planlanıyor. Tekrarlanan PAP cihazı ile yapılan PSG (Figür 2) incelemesinde anormal solunum olayı olmayıp, uyku başlangııında SO-REM periyodu kayıtlanıyor. $\mathrm{Bu}$ çekimin ertesi günü yapılan çoklu uyku latans testinde ortalama uyku başlangıç latansı 0,8 dakika olup 2 adet SO-REM periyodu kayıtlanması ve anamnezde katapleksi ataklarının eşlik 


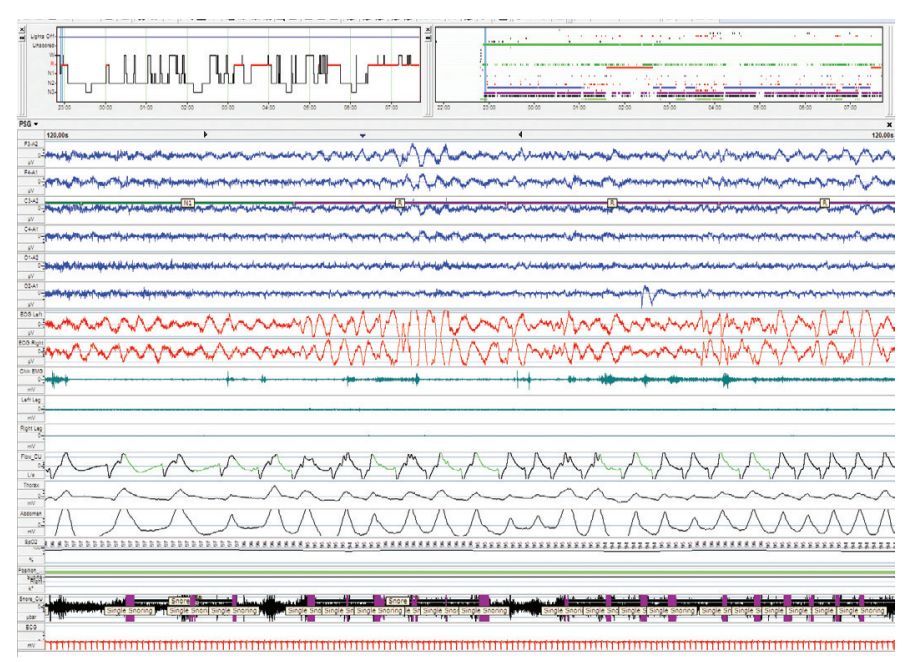

Figür 2. Olgu 2 pozitif havayolu basıncı cihazı ile polisomnografi incelemesi

etmesi üzerine hasta narkolepsi tip 1 tanısı alıyor. Hastanın takiplerinde modafinil 400 mg/gün, armodafinil 250 mg/gün tedavisi ile yanıt alınamaması üzerine sodyum oksibat tedavisine başlanıyor, klinik kısmi yanıt görüyor.

Hastanın katapleksi atakları olmayıp gündüz aşırı uykululuğu sodyum oksibat ve armodafinil tedavisi ile kısmı düzelmiş olması nedeniyle pitolisant için yurt dışından talep başvurusu yapılıyor ancak hastanın maddi olarak karşılayamaması üzerine pitolisant getirilemeyerek klinik takibi devam ediliyor.

\section{Olgu 3}

Kırk yedi yaşında, sağ el dominant, bankada çalışan kadın hasta; lise yıllarında başlayan ancak önemsemediği gündüz uykululuğu ve özellikle gülmekle tetiklenen kol ve bacaklarında parsiyel veya jeneralize olabilen katapleksi atakları nedeniyle kliniğimize başvuruyor. Özgeçmişinde derin ven trombozu, hashimoto tiroiditi, insülin direnci olan hastanın soygeçmişte özelliği olmayıp boyu 167 cm vücut ağırlı̆̆ı 110 kg; sistemik ve nörolojik muayenesi normal olarak saptanıyor. Laboratuvar tetkiklerinde tiroit fonksiyon testleri ve biyokimyası normal, kranial MRG normal olarak tespit ediliyor. Hastanın kliniğimize ilk başvurusu 2006 yılında ve o dönem gündüz aşırı uykululuk ve horlama nedeniyle başvurusunda yapılan PSG incelemesinde anormal solunum olayı olmadan horlama kayıtlanması üzerine basit horlama tanısı alıyor. Hastanın yaklaşık 12 yıl sonra yeniden kliniğimize gündüz aşırı uykululuk ve katapleksi nedeniyle başvurusunda yapılan PSG incelemesinde AHI 21 olarak tespit ediliyor ve orta dereceli Uyku Apne sendromu saptanması üzerine PAP titrasyon tedavisi uygulanıyor. Hastanın gündüz aşırı uykululuk ve katapleksi şikayetlerinin devam etmesi üzerine PAP cihazı ile PSG çekimi ve ÇULT planlanıyor. Hastanın PAP cihazı ile yapılan PSG anormal solunum olayı saptanmayıp (Figür 3) çekimin başında SO-REM periyodu kayıtlanıyor, ertesi gün devam edilen ÇULT ortalama uyku başlangıç latansı 0,8 dakika ve 5 adet SO-REM periyodu saptanması üzerine narkolepsi tip 1 tanısı alıyor.

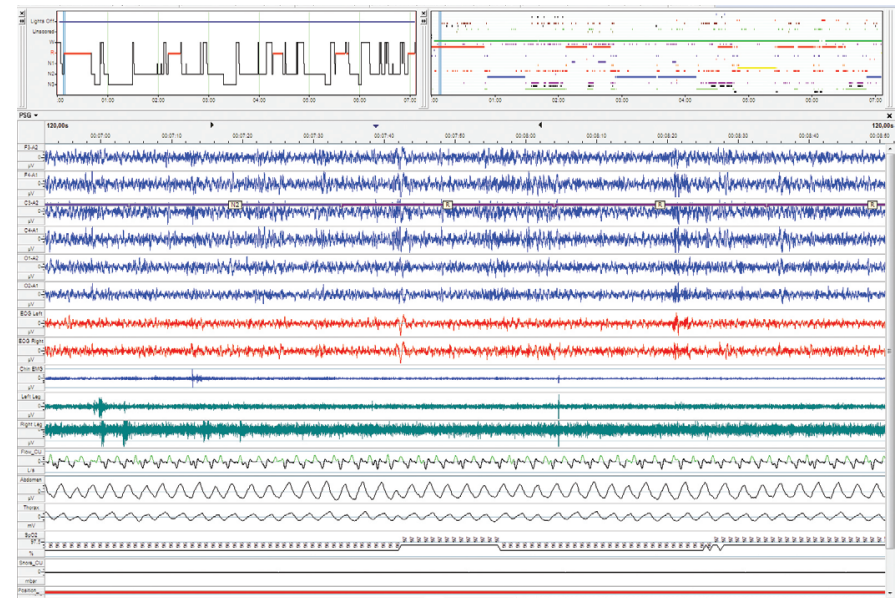

Figür 3. Olgu 3 pozitif havayolu basıncı cihazı ile yapılan polisomnografi incelemesi

Hastaya mevcut katapleksi nedeniyle venlafaksin tedavisi ve gündüz aşırı uykululuğu nedeni ile kullanılan modafinil yanıtsızlığı üzerine armodafinil $250 \mathrm{mg} /$ gün tedavisine geçiliyor. Hasta PAP tedavisi, venlafaksin ve armodafinil tedavisi ile yakınması olmadan takip edilmektedir.

\section{Olgu 4}

Otuz beş yaşında, sağ el dominant, erkek hasta; on yedi yaşında başlayan ancak önemsemediği gündüz ani uyku atakları, uykuya dalarken hayal görme, çene ve bacaklarında ani tonus kayıpları ile kliniğimize başvuruyor. Özgeçmişinde depresyon öyküsü olan hastanın soygeçmişte özelliği olmayıp boy $195 \mathrm{~cm}$ vücut ağırlığı 92 kg; sistemik ve nörolojik muayenesi normal saptanıyor. Laboratuvar tetkiklerinde tiroit fonksiyon testleri ve biyokimyası normal, kranial MRG normal olarak tespit ediliyor. Hasta kliniğimize ilk başvurusu 2004 yılında ve PSG incelemesinde anormal solunum olayı saptanmıyor. Ertesi gün yapılan ÇULT incelemesinde 3 SO-REM periyodu saptanıyor. Ortalama uyku başlangıç latansı 1,6 dakika olarak tespit ediliyor. Hasta tip 1 narkolepsi tanısı ile uygulanan modafinil, armodafinil, metilfenidat tedavilerine fayda almaması üzerine sodyum oksibat tedavisi planlanıyor ancak o dönem ilaca ulaşım zorluğu nedeni ile düzenli tedavi alamıyor; sedanter yaşam etkisi ile de kilo alıyor. Hastanın 2007 yılında tekrarlanan PSG incelemesinde ağır Uyku Apne sendromu saptanıyor ve narkolepsi tedavisine ek olarak PAP tedavisi planlanıyor. İzlemde PAP tedavisi ile anormal solunum olayı devam etmeyen hastaya sodyum oksibat tedavisi ekleniyor ve gündüz aşırı uykululuğu ve katapleksi yakınmaları kontrol altına alınıyor.

\section{Tartışma}

Gündüz aşırı uykululuğu ile başvuran hastaya yaklaşımda uykuya başladığı saat ve uyandığı saat ile gece süresince uyku yapısı sorgulanarak, uyku yapısının bölünmesine neden olacak olası nedenler; santral hipersomni nedenleri, başka nedenle kullanılan ilaçlar, hipotalamik yapısal lezyonlar göz önünde 
bulundurulmalıdır (3). Illk olgumuzun nöropatik ağrı nedeniyle kullandığı pregabalin sabah dozunun gündüz uykululuğunda artışa neden olabilmesi nedeniyle pregabalin azaltılarak kesilmiştir (4).

Gece uykularının bölünmesi veya normalden kısa süreli uyumak, uyku deprivasyonu yaparak gündüz uykululuğa neden olabilmektedir. Uyku Apne sendromu olan hastalarda da apne sonrasındaki arousal aktiviteleri ile oluşan mikro uyanıkıklar neticesinde rezidü uykululuk, gündüz aşırı uykululuğunun sık nedenlerindendir. Narkolepsi ise santral hipersomni nedenleri arasında gündüz aşırı uykululuğuna neden olabilecek bir diğer önemli nedendir. Narkolepsideki gündüz aşırı uykululuğu klasik olarak 20-30 dakikadan kısa süreli, dinlendirici nitelikte ve ek olarak katapleksi atakları olsun olmasın, REM uyku evresine özgü hipnogojik veya hipnopompik halüsinasyonlar, uyku paralizisi gibi semptomlarların eşlik edebildiği ve süreç içerisinde fragmente gece uykusunun eklendiği bir tablodur. Uyku Apne sendromlu hastalar ise genellikle yorgun ve başağrısı ile uyanırlar, gündüz uyku atakları uzun süreli ve dinlendirici değildir. Eşlik eden katapleksi veya diğer REM uyku evresine ait özellikler yoktur. Narkolepsi daha çok adölesan yaş grubunda olmak üzere 15-35 yaş grubunda görülmekte ancak narkopelsi tanısının adolesan dönemde konulamaması nedeniyle tanı yaşı gecikebilir. OUAS ise daha çok orta yaş grubunda görülür, artan yaş ile görülme prevelansı da artar $(5,6)$.

Narkolepsi ve OUAS kliniklerinin farkları olsa da bu iki antitenin birlikte olabildiği olgular mevcuttur. Narkolepsi hastalarının yaklaşık \%20-30'unda OUAS ko-morbidite olarak eşlik etmektedir. Özellikle de artan Vücut Kitle indeksi, yaş ve erkek cinsiyet ile ilişkisi bildirilmektedir (7-11). Literatürdeki verileri destekler nitelikte olan ilk ve ikinci olgumuzda OUAS'li bir hastanın PAP tedavisine rağmen gündüz aşırı uykululuğunun devam ettiği noktada akla ilk cihazın verimli kullanılmaması veya cihazın çalısmaması sonucu rezidü uykululuk gelmekte iken; hastaların cihaz dökümünde kullanım kaydının görülmesi ve cihazı ile hastayı PSG çekimine aldığımızda anormal solunum olayı görmememiz cihazın kullanılmasına ve çalışmasına rağmen şikayetlerin devam ettiğini göstermekte ve PAP tedavi yetersizliği seçeneğinden uzaklaştırmaktadır. Öyküde katapleksi ataklarının eşlik etmesi ve cihaz ile yapılan PSG incelemesinin devamında ertesi gün uygulanan ÇULT incelemesinde 2 'den fazla SO-REM periyodu kayıtlanması ve uyku başlangıç latansının $8^{\prime}$ in altında olması da eşlik eden narkolepsi tip 1 varlığını göstermektedir. Dördüncü olgumuzla birlikte üç olgumuz da erkek cinsiyette, Vücut Kitle indeksleri 30 üzerinde olan olgulardır.

Üçüncü ve dördüncü olguda ise gündüz aşırı uykululuğunun ve katapleksi ataklarının lise yıllarında başlaması ve ilk yapılan PSG incelemesinde anormal solunum olayı olmamasına rağmen sonraki yıllarda yapılan PSG incelemesinde Uyku Apne sendromu varlı̆̆ı tedavi edilmeyen tip 1 narkolepsi olgularının hasarlı hipokretin mekanizması üzerinden kilo alımına neden olarak (12-14) OUAS gelişimi için bir risk faktörü olması nedeniyle bu duruma zemin hazırlayabilme olasıı̆ı̆ı akla getirmektedir. Ek olarak oreksin defisitinde hiperkapniye karşı oluşan ventilasyon cevabında azalma ve intermittent hipoksi maruziyetinde ventilasyonun uzun dönem fasilitasyonunda azalmanın (15) ve deneysel modellerde gösterilen oreksin A ve $B^{\prime}$ nin faringeal açıklığın sağlanmasında önemli rol olan genioglossus kasını innerve eden hipoglossus sinirinin aktivitesine katılımının da narkolepsi olgularında OUAS'ye neden olabileceği tartışılmaktadır (16). Ülkemiz literatüründe 24 yaşında multiple skleroz tanısı alan bir erkek olgu tip 1 narkolepsi ve hafif dereceli Uyku Apne sendromu birlikteliği bildirilmiştir (17).

Gündüz aşırı uykululuğu birçok nedenden kaynaklanabilmekte; bir kısmı birliktelik bir kısmı da süreç içerisinde bir sonuç olarak karşımıza çıkmaktadır. Klinisyen olarak dikkat etmemiz gereken, hastaların tanı ve tedavi sonrasında şikayetlerinin devam edip etmediğini takip ederek verilen tedaviye yanıtsızlık durumunda eşlik eden bir başka problemi sorgulamaktır.

OUAS'de gündüz aşırı uykululuğunun nedeni genellikle PAP tedavisindeki sorunlar iken uygun basınç ve sürede tedaviye rağmen devam eden durumlarda narkolepsi birlikteliği de akılda bulundurulmalıdır. Özellikle gündüz aşırı uykululuğu ile başvuran genç hastada orta dereceli AHI tespit edildiğinde akılda OUAS eşlik eden bir narkolepsi varlığından kuşkulanılması; ileri yaşlı ve Vücut Kitle indeksi yüksek bir hastada da narkolepsiye eşlik eden bir OUAS varlığının göz önünde bulundurulması vurgulanmaktadır.

\section{Etik}

Hasta onayı: Hastaların medikal bilgilerinin bilimsel amaçı kullanılabilmesi amacı ile onayları alınmıştır.

Hakem Değerlendirmesi: Editörler kurulu tarafından değerlendirilmiştir.

\section{Yazarlık Katkıları}

Veri Toplama veya Isşleme: D.M.D., O.B., I.Ö., B.B., Analiz veya Yorumlama: D.M.D., O.B., S.F., A.Ö.Ç., I.Ö., B.B., Yazan: D.M.D., O.B., I.Ö., B.B.

Çıkar Çatışması: Yazarlar arasında çıkar çatışması yoktur. Finansal Destek: Bu çalışma için herhangi bir kurumdan finansal destek alınmamıştır.

\section{Kaynaklar}

1. Moller HJ, Lam S. Quality of life in excessive daytime sleep and hypersomnia. In: Verster JC, Perumal SRP, Streiner DL (eds). Sleep and Quality of Life in Clinical Medicine. Humana Press, Totowa NJ, 2008:107-118.

2. Ohayon MM. Epidemiological overview of sleep disorders in the general population. Sleep Med Res. 2011:2:1-9.

3. Slater G, Steier J. Excessive daytime sleepiness in sleep disorders. J Thorac Dis 2012;4:608-16.

4. Jokela R, Ahonen J, Tallgren M, Haanpää M, Korttila K. A randomized controlled trial of perioperative administration of pregabalin for pain after laparoscopic hysterectomy. Pain 2008;134:106-12.

5. Dauvilliers Y, Montplaisir J, Molinari N, Carlander B, Ondze B, Besset A, Billiard M. Age at onset of narcolepsy in two large populations of patients in France and Quebec. Neurology 2001;57:2029-33.

6. Young T, Skatrud J, Peppard PE. Risk factors for obstructive sleep apnea in adults. JAMA 2004;291:2013-6.

7. Frauscher B, Ehrmann L, Mitterling T, Gabelia D, Gschliesser V, Brandauer E, Poewe W, Högl B. Delayed diagnosis, range of severity, and multiple sleep comorbidities: a clinical and polysomnographic analysis of 100 patients of the innsbruck narcolepsy cohort. J Clin Sleep Med 2013;9:805-12. 
8. Pataka AD, Frangulyan RR, Mackay TW, Douglas NJ, Riha RL. Narcolepsy and sleep- disordered breathing. Eur J Neurol 2012;19:696-702.

9. Santamaria J, Iranzo A, Ma Montserrat J, de Pablo J. Persistent sleepiness in CPAP treated obstructive sleep apnea patients: evaluation and treatment. Sleep Med Rev 2007;11:195-207.

10. Jennum P, Ibsen R, Knudsen S, Kjellberg J. Comorbidity and mortality of narcolepsy: a controlled retro- and prospective national study. Sleep 2013;36:835-40

11. Cohen A. Mandrekar J, St Louis EK, Silber MH, Kotagal S. Comorbidities in a community sample of narcolepsy. Sleep Med 2018;43:14-8.

12. Kok SW, Overeem S, Visscher TL, Lammers GJ, Seidell JC, Pijl H, Meinders AE. Hypocretin deficiency in narcoleptic humans is associated with abdominal obesity. Obes Res 2003;11:1147-54.

13. Aran A, Einen M, Lin L, Plazzi G, Nishino S, Mignot E. Clinical and therapeutic aspects of childhood narcolepsy-cataplexy: a retrospective study of 51 children. Sleep 2010;33:1457-64.
14. Poli F, Pizza F, Mignot E, Ferri R, Pagotto U, Taheri S, Finotti E, Bernardi F, Pirazzoli P, Cicognani A, Balsamo A, Nobili L, Bruni O, Plazzi G. High prevalence of precocious puberty and obesity in childhood narcolepsy with cataplexy. Sleep 2013;36:175-81.

15. Nakamura A, Zhang W, Yanagisawa M, Fukuda Y, Kuwaki T. Vigilance State- dependent Attenuation of Hypercapnic Chemoreflex and Exaggerated Sleep Apnea in Orexin Knockout Mice. J Appl Physiol (1985) 2007;102:241-8.

16. Zhang GH, Liu ZL, Zhang BJ, Geng WY, Song NN, Zhou W, Cao YX, Li SQ, Huang ZL, Shen LL. Orexin A Activates Hypoglossal Motoneurons and Enhances Genioglossus Muscle Activity in Rats. Br J Pharmacol 2014;171:4233-46.

17. Genç S, Bilgiç Kayım H, Okuyucu EE, Dikmen N, Duman T. A Case of Secondary Narcolepsy Presenting with Obstructive Sleep Apnea Symptoms. J Turk Sleep Med 2016;3:23-5. 